\title{
Paternalist Liderlik Algısının Çalışan Sesliliğine Etkisi: Gıda Sektörü Çalışanları Üzerine Bir Araştırma*
}

\author{
Bilge ÖZYILMAZ** Lale ORAL ATAÇ ${ }^{* * *}$
}

$\ddot{O} Z$

Bu araştırmanın amacı, paternalist liderlik algısının çalışan sesliliği üzerindeki etkisini ortaya koymaktır. Bu amaçla tamamı gıda sektöründe faaliyet gösteren işletmelerde çalışan 123 katılımcıdan anket tekniği ile veri toplanmıştır. Kullanılan anket formu, Paternalist Liderlik Ölçeği ve Çalışan Sesliliği Ölçeği ile birlikte örneklemin demografik özelliklerini ölçmek üzere hazırlanmış sorulardan oluşmaktadır. Analiz sonuçlarına göre, paternalist liderlik ölçeğinin tüm alt boyutları (iş yerinde aile ortamı, iş dışı yaşama katılma, sadakat ve itaat beklentisi) ile çalışan sesliliği arasında pozitif yönlü anlamlı korelasyon bulunmaktadır. Ayrıca paternalist liderliğin iş dışı yaşama katılma alt boyutu, çalışan sesliliği üzerinde pozitif yönlü anlamlı etkiye sahiptir.

Anahtar Kelimeler: Paternalist liderlik, çalışan sesliliği, gıda sektörü.

JEL Sinıflandırması: M10, M54

\section{The Effect Of Paternalıstıc Leadershıp On Employee Voıce: A Research On Employees In The Food Industry}

\begin{abstract}
The aim of this study is to reveal the effect of employee's perception of paternalist leadership on their voice behavior. For this purpose, a survey was applied to 123 participants working in the food industry. The questionnaire consists of Paternalist Leadership Scale, Employee Voice Scale and demographic questions. According to the results, there are significant positive correlations between all sub-dimensions of paternalist leadership scale (family environment at workplace, involvement in non-work domain of employees' lives, expectation of loyalty and deference) and employee voice. In addition to this, as a sub-dimension of the paternalistic leadership, "involvement in non-work domain of employees' lives" has significantly positive effect on employee voice.
\end{abstract}

Keywords: Paternalistic leadership, employee voice, food industry.

JEL Classification: M10, M54

\section{GİRIŞ}

Liderin bir örgütte yapılan işlerin bütününe hakim olması bugünkü koşullarda hemen her sektörde çok güç hale gelmiştir. Verilen kararların niteliği ve örgüt işleyişinin etkinliği konusunda astların düşünce ve görüşlerine olan ihtiyacın artışına paralel olarak, günümüzün yüksek profilli çalışanı için işi ile ilgili konularda söz sahibi olma pratiği, iş motivasyonunu ve örgüte karşı tutumu şekillendiren önemli bir faktör olarak belirmektedir. Bu noktada, çalışanların pozitif bir tutum ve proaktif bir yaklaşımla işe ilişkin bilgi, görüş ve önerilerini dile

\footnotetext{
* Bu çalışma, Dr. Öğr. Üyesi Lale Oral Ataç danışmanlığında yürütülen "Paternalist Liderlik Algısının Çalışan Sesliliğine Etkisi: Gıda Sektörü Çalışanları Üzerine Bir Araştırma" başlıklı yüksek lisans tezinden türetilmiştir.

** Manisa Celal Bayar Üniversitesi, Sosyal Bilimler Enstitüsü, Yönetim ve Organizasyon Yüksek Lisans Programı, bilgeozyilmazz@gmail.com

*** Dr. Öğr. Üyesi, Manisa Celal Bayar Üniversitesi, Salihli İ̈BF İșletme Bölümü, lale.oral@cbu.edu.tr 
getirmeleri olarak tanımlanabilecek çalışan sesliliği kavramı önemli bir olgu olarak ortaya çıkmaktadır. Araştırma sonuçları çalışan sesliliğini; verilen kararların kalitesini artırma, örgütsel öğrenme ve gelişime katkı sağlama, çalışanların işe karşı olumlu tutumlar geliştirmelerine yardımcı olma gibi pek çok olumlu çıktı ile ilişkilendirmektedir (Morrison, 2011). Diğer taraftan, çalışanların yapıcı fikirlerini paylaşma, yani seslilik ortamına destek verme eğilimleri, yöneticileri tarafindan görüşlerine değer verildiği, esenliklerinin önemsendiği yönündeki örgütsel destek algıları arttıkça güçlenmektedir (Duan vd., 2014). Bir örgütte, çok seslilik ikliminin inşası, doğru liderlik biçiminin benimsenmesi ve doğru ast-üst iletişiminin tesis edilmesi ile yakından ilişkili görünmektedir.

Toplumsal kültürümüzün bir parçası olan paternalist değerlerin iş yaşamında da kendisini hissettirdiği ve ülkemizde örgüt kültürünü şekillendiren önemli bir faktör olduğu bilinmektedir (Aycan ve Kanungo, 2000). Yapılan araştırmalar, genç nesli temsil edenler de dahil olmak üzere, ülkemiz çalışanlarının, liderlerinden, kendilerine aile sıcaklığ 1 hissettirmesi, hem iş hem özel yaşama ilişkin ihtiyaçlarına kol kanat germesi gibi babacan tavırlar beklediğini göstermektedir (Gürcan, 2018). Bu anlamda, disiplin ve otoriteyi babacan bir ilgi ve yardımseverlik ile bütünleştiren paternalist liderlik modeli (Westwood, 1997), ülkemizde hakim liderlik ikliminin anlaşılmasında özel öneme sahiptir. Buna rağmen, söz konusu liderlik iletişimi içerisinde çalışan sesliliği davranışlarının ne şekilde gerçekleştiği büyük ölçüde karanlıkta kalmaktadır.

Araştırmanın amacı, paternalist liderlik algısının çalışan seslilĭgi üzerindeki muhtemel etkisini ortaya koymaktır. Bu kapsamda, çalışanların paternalist liderlik algıları ve buna ilişkin alt boyutlar ile çalışan sesliliği arasında ilişki var mıdır, varsa bu ilişkilerin yönü nedir; söz konusu değişkenler çalışan sesliliğini açıklamakta istatistiksel olarak anlamlı kabul edilebilir mi gibi sorulara yanıt aranmaktadır. Araştırma, büyük oranda sessizlik olgusuna odaklanılmış bir ulusal araştırma çevresi içerisinde, çalışan sesliliğine ilişkin veriler sunuyor olması bakımından önem arz etmektedir. Öte yandan, ulusal kültürel bağlam içerisinde, tarih boyunca olduğu gibi bugün hala önemli bir yere sahip paternalist liderlik biçiminin örgüt ortamında seslilik olgusu üzerindeki etkilerini ortaya koyması bakımından literatüre ve örgüt içerisinde çok seslilik iklimi yaratmaya çalışan uygulayıcılara katkı sağlayacağı düşünülmektedir.

\section{KAVRAMSAL ÇERÇEVE}

\section{A. Paternalist Liderlik}

En basit şekli ile paternalist liderlik, izleyicilere bir aile büyügü veya baba gibi davranmak şeklinde tanımlanabilir (Aycan, 2006). Bir anlamda paternalist lider, astların, iş yerinin kapıları ardındaki yaşamlarına da dahil olan, kişisel problemlerine ilgi gösteren, iş ve iş harici yaşama dair hedeflerini gerçekleştirmelerinde onlara destek olan lider türüdür (Paşa vd., 2001). Paternalist kültürün biçimlendirdiği bağlam içerisinde bu lider-üye ilişkisinin temelinde, liderin astlarına koruma sağlaması ve astların ise bunun karşılığında kendilerini lidere sadakat ve itaat göstermekle borçlu hissetmeleri yatmaktadır (Pellegrini ve Scandura, 2006). Buraya kadarki açıklamaları özetleyecek olursak, liderin adeta bir 
ebeveyni andıran ilgi ile izleyicilerinin mesleki ve özel yaşamlarına rehberlik ettiği; bunun karşılığında ise sadakat ve saygı beklediği hiyerarşik bir ilişki biçimi anlaşılmaktadır (Gelfand vd., 2007).

Aycan'a (2006) göre paternalist liderliği karakterize etmede beş temel davranış ön plana çıkmaktadır. Bunlar; iş yerinde aile ortamı yaratmak, astlar ile yakın ve bireyselleşmiş ilişkiler kurmak, çalışanların iş dışı yaşamlarına katılmak, sadakat beklemek ve statü farklılıklarına önem vererek otoriter davranmaktır. Farh ve Cheng (2000) ise paternalist liderliğii; "otoriterlik", "yardımseverlik", "dürüstlük ve ahlak" olmak üzere üç boyutlu bir model olarak incelemektedirler. Bu modele göre paternalist liderin; yetki devretmekten kaçınan, dikey iletişime ağırlık veren, yüksek düzeyde kendine güven sergileyen, astlarından yüksek performans beklentisi içerisinde olan ve performanslarını geliştirmeleri için onlara rehberlik eden otoriter bir yanı vardır. Ayrıca, çalışanlarına aile bireyleriymişçesine muamele gösteren, özel problemlerinin çözümünde rehberlik eden, hem iş hem de iş dışını kapsayacak biçimde astlarının yaşamına bütüncül bir ilgi sergileyen, hata yapmaları durumunda onlara sahip çıkan yardımseverlik yanı söz konusudur. Dürüstlük ve ahlak boyutu ise astlarının çıkarlarını bireysel çıkarlarının önünde tutma, otoritesini kötüye kullanmaktan kaçınma ve gerek kişiliği gerekse işine karşı tutumu ile izleyicilerine örnek teşkil etme gibi özellikleri ile ilgilidir.

Paternalist bir kültürel bağlamın varlığında, paternalist liderlik davranışının çalışanların işe karşı tutumları üzerinde olumlu etkiye sahip olduğu görülmektedir. Yapılan araştırmalar, paternalist liderliğin astların iş doyumunu yükselttiği (Uhl-Bien vd., 1990), lider-üye etkileşimini güçlendirdiği (Martinez, 2003), örgütsel bağl1lık (Pellegrini vd., 2010) ve güven (Apaydın, 2017) düzeyini artırdığı yönünde sonuçlar vermektedir.

\section{B. Çalışan Sesliliği}

İngilizce kaynaklarda "employee voice" olarak karşımıza çıkan kavramın Türkçe karşılığı konusunda literatürde fikir birliği sağlanamadığı anlaşılmaktadır. $\mathrm{Bu}$ durum, çalışan sesliliği olgusunun bir araştırma alanı olarak ilgi görmeye başlamasının çok eskilere dayanmayışı ile ilgili olabilir. Söz konusu olgunun karş1lı̆̆ olarak çeşitli yayınlarda; çalışan sesi, çalışanın ses verme davranış1, çalışanın ses çıkarma davranışı veya işgören sesliliği gibi kullanımlara rastlamaktayız (Şehitoğlu, 2012; Bulut ve Meydan, 2018; Ergül vd., 2017; Arslan ve Yener, 2016).

En basit tanımı ile çalışan sesliliği, örgüt çalışanlarının iş yerindeki çeşitli konulara ilişkin görüş veya önerilerini bilinçli olarak ifade etmeleridir (Van Dyne vd., 2003). Bu fikir veya öneriler, mevcut durumu eleştirmekten ziyade geliştirme amacı taşıyan, değişime yönelik, yenilikçi katkı çabaları biçiminde anlaşılmalıdır (Van Dyne ve LePine, 1998). Diğer bir ifade ile çalışan sesliliği, çalışanların fikirlerini yapıcı amaçlarla dile getirmeleri davranışının karşılığında kullanılan kavramdır (Tangirala ve Ramanujam, 2008). Ayrıca bunlar, herhangi bir zorunluluk dolayısıyla değil fakat isteğe bağlı olarak ortaya konan davranışlardır (Morrison, 2011). 
Van Dyne ve arkadaşları (2003); olumlu sosyal seslilik, savunmacı seslilik ve kabullenici seslilik olmak üzere üç seslilik türü tanımlamışlardır. Buna göre olumlu sosyal seslilik, kişinin tüm örgütün çıkarına olacak şekilde ve iş birliği yapmak amacıyla fikir, bilgi veya görüşlerini ortaya koymasıdır. Çeşitli konularda çözüm önerileri veya değişim olanakları sunmak, bu tür sesliliğe örnektir. Kişinin kendini savunma kaygısı ile görüş beyan etmesi ise savunmacı seslilik olarak adlandırılmaktadır. Kabullenici seslilik ise kişinin fikir birliğini veya desteğini ifade etme yönündeki davranışlarına verilen addır.

Literatürdeki bilgiler, çalışan sesliliğinin, örgütteki tatminsizlik yaratan bir durum neticesinde çalışanlarda otaya çıkabilecek yapıcı bir tepki biçimi olduğunu ve ifade özgürlügü bakımından elverişli bir ortam sunan kültürlerde, yönetimin etkinliğini artıran önemli bir araç olarak ortaya çıktığını göstermektedir (Oral Ataç, 2018). Ayrıca, seslerinin dikkate alınması, bir örgütün çalışanlarının örgüt amaçlarını benimseme düzeylerini ve örgüte olan bağlılıklarını güçlendiren önemli bir faktördür (Farndale vd., 2011).

\section{Liderlik ve Çalışan Sesliliği Arasındaki İlişki}

Çalışan sesliliğine etkisi olan faktörleri bireysel ve bağlamsal faktörler olmak üzere iki grupta sınıflandırmak mümkündür (Morrison, 2011). Literatürdeki araştırmalardan, çalışanların işlerine karşı tutumları, örgüte olan bağl1lıkları, performans düzeyleri, iş tecrübeleri ve örgüt hiyerarşisi içerisindeki konumları gibi bireysel birtakım değişkenlerinin seslilikleri üzerinde etkili olduğu anlaşılmaktadır (Kassing, 1998; Detert ve Burris, 2007; LePine ve Van Dyne, 1998; Fuller vd., 2006). Çalışan sesliliğine etki eden bağlamsal faktörlerin ise örgütteki egemen liderlik anlayışı ile yakından ilişkili değişkenler olduğu göze çarpmaktadır. Örneğin örgüt yapısının dikliği, çalışanların fikirlerini paylaşma olanaklarını sınırlarken basıklığ 1 bu anlamda daha elverişli şartlar sunmaktadır (Morrison ve Milliken, 2000). Liderin astları ile iletişime açık ve onları dinlemeye istekli oluşu ile örgütte, çalışanların fikirlerini paylaşmalarını destekleyici bir kültürün inşa edilmesi bu anlamda önemli faktörler olarak karşımıza çıkmaktadır (Detert ve Burris, 2007; Dutton vd., 1997). Esasen çalışanların çeşitli konulardaki yapıcı fikirlerini, örgüleri içerisinde etkin olarak paylaşabilecekleri yönünde bir inanç geliştirmeleri, liderin, çok sesliliğin desteklendiği bir örgüt iklimi yaratmasının neticesinde mümkün olmaktadır (Frazier ve Fainshmidt, 2012).

Bir örgütte, çalışan davranışları üzerindeki en önemli bağlamsal etkenlerden birinin yöneticilerin hakim liderlik stili olduğunu; bu anlamda ana otorite figürü olarak liderin, örgütsel davranış üzerinde merkezi rolü elinde tuttuğunu söylemek yerinde olacaktır (Zhang vd., 2015). Bir görüşe göre, liderin çalışan sesliliği üzerindeki etkisi iki temel olguya dayanmaktadır. İlk olarak, lider, çalışanın dile getirdiği sorunu çözecek yegane kişi olarak seslilik olgusunun önemli bir tarafıdır. İkinci olarak ise, örgütte ödül ve ceza kaynaklarını elinde bulunduran kişi olması sebebiyle, seslilik davranışına bunların hangisi ile karşıllk vereceğine bağlı olarak, çalışanları bu anlamda daha istekli veya isteksiz kılan kişidir (Xiao ve Pan, 2017). 
Mevcut literatür, çeşitli liderlik biçimleri ile çalışan sesliliği arasındaki ilişkileri ortaya koymaktadır. Detert ve Burris (2007) tarafından üç bini aşkın restoran çalışanı üzerinde yapılan araştırma, dönüşümcü liderliğin çalışan sesliliği davranışını olumlu yönde etkilediğini ortaya koymaktadır. Duanxu ve arkadaşlarının (2015) Çinli çalışanlar üzerine yaptıkları araştırma etik liderliğin de çalışan sesliliği üzerinde benzer bir etkisi olduğunu göstermektedir. Henderson (2013) ise ABD'li çalışanlar üzerinde yaptığ 1 araştırmada, hizmetkar liderliğin çalışan sesliliği üzerinde güçlü bir etkisi olduğunu tespit etmiştir. Bulut ve Meydan'ın (2018) Türkiye'de kamu sektörü çalışanları üzerinde yaptıkları araştırmada ise çalışan sesliliği ile görev odaklı liderlik tarzı arasında pozitif yönlü anlamlı ilişki olduğu görülmüştür.

Chan (2013), Hong Konglu çalışanlar üzerinde yaptığı araştırmada, paternalist liderliğin ahlaki boyutunun çalışan sesliliğini olumlu yönde, otoriterlik boyutunun ise olumsuz yönde etkilediğini bulmuştur. Liu ve Liu (2017) ise Çinli çalışanlar üzerinde yaptıkları araştırmada, paternalist liderliğin ahlaki ve yardımsever boyutunun çalışan sesliliğini olumlu yönde; otoriterlik boyutunun ise olumsuz yönde etkilediğine ilişkin sonuçlara ulaşmışlardır. Literatürde bu ilişkiyi ölçen fazla araştırma bulunmadığ 1 göze çarparken, Türkiye örnekleminde bu ilişkinin gerçekleşme biçimi ayrıca merak konusu olmaktadır. Diğer bir ifade ile yapılan araştırmalar, çalışan sesliliği ile liderlik stilleri arasında yakın bir ilişki olduğunu ortaya koymakla birlikte, bizim kültürümüz içerisinde ön plana çıan önemli bir olgu olarak paternalist liderliğin muhtemel etkileri konusunda yeterli veriyi sunmaktan uzaktır. Bu araştırmanın temel motivasyonu, bu noktadan hareketle, paternalist liderlik biçiminin çalışan sesliliği ile ilişkisini ve söz konusu olgu üzerinde herhangi bir etkisi olup olmadığını ortaya koyma arzusudur. Buraya kadar yapılan açıklamaların ışığında, aşağıda yer alan hipotezler geliştirilmiş ve araştırmanın ilerleyen kısımlarında test edilmiştir:

$H_{1}$ : Paternalist liderlik algısının, işyerinde aile ortamı yaratma boyutu ile çalışan sesliliği arasında pozitifyönlü anlamlı iliş̧ki vardır.

$\mathrm{H}_{2}$ : Paternalist liderlik algısının, çalışanların iş dışı yaşamlarına katılma boyutu ile çallşan sesliliği arasında pozitifyönlü anlamlı iliş̧ki vardır.

$H_{3}$ : Paternalist liderlik algısının, çalışanlarından sadakat ve itaat beklentisi boyutuyla çalışan sesliliği arasında pozitif yönlü anlaml ilişsk vardir.

$H_{4}$ : Paternalist liderlik algısı, çalışan sesliliğini açılamada istatistiksel olarak anlamlı bir değişkendir.

\section{YÖNTEM}

$\mathrm{Bu}$ araştırma nicel yönteme uygun olarak tasarlanmıştır ve anket tekniği ile toplanan kesitsel verilerin analize tabi tutulması neticesinde elde edilen bulgular, ilerleyen başlıklar kapsamında sunulmuştur. Araştırma örneklemine uygulanan anket formu iki ölçekten ve demografik verileri ölçmek üzere hazırlanmış 8 maddelik bir soru formundan oluşmaktadır. Anketler, yapılan firma ziyaretlerinde, araştırmacı tarafindan katılımcılara elden dağıtılmış ve geri toplanmıştır. Elde 
edilen veriler IBM SPSS ve Amos paket programları yardımı ile doğrulayıcı faktör, güvenilirlik, korelasyon ve hiyerarşik regresyon analizlerine tabi tutulmuştur.

\section{A. Örneklem}

Araştırma anketleri, Manisa ilinde muhtelif gida üretim işletmelerinde çalışan beyaz ve mavi yakalı 175 çalışana ulaştırılmış; veri toplama sürecinin sonunda 136 kullanılabilir anket formu elde edilmiştir. Verilerin analize hazırlanması aşamasında Mahalanobis uzaklıkları üzerinden uç değerler tespit edilmiş ve 13 anket formu analiz dışı bırakılmıştır. Böylece analizler, 123 katılımcının yanıtları üzerinden gerçekleştirilmiştir.

Örneklemin demografik özellikleri Tablo 1'de özetlenmektedir. Buna göre örneklemin \%41,5'i kadın, \%58,5'i erkektir. Yaşları 18 ila 61 arasında değişen katılımcıların yaş ortalaması 35,5'tir. Yaklaşık \%67'si evli olan örneklemin büyük bölümünün ilköğretim ve lise mezunu olduğu (yaklaşık \%75 oranında) ve yaklaşık \%71'inin mavi yakalı çalışan olduğu görülmektedir.

Tablo 1: Örneklemin demografik yapısı

\begin{tabular}{|c|c|c|c|}
\hline Değișken & & Sıklık & $\operatorname{Oran}(\%)$ \\
\hline \multirow{2}{*}{ Cinsiyet } & Kadın & 51 & 41,5 \\
\hline & Erkek & 72 & 58,5 \\
\hline \multirow{2}{*}{ Yaş } & $18-39$ yaş arası & 82 & 66,7 \\
\hline & 40-61 yaş arası & 41 & 33,3 \\
\hline \multirow{2}{*}{ Medeni Durum } & Evli & 82 & 66,7 \\
\hline & Bekar & 41 & 33,3 \\
\hline \multirow{5}{*}{ Eğitim Durumu } & İlköğretim & 55 & 44,7 \\
\hline & Lise & 37 & 30,1 \\
\hline & Ön lisans & 14 & 11,4 \\
\hline & Lisans & 16 & 13,0 \\
\hline & Lisansüstü & 1 & 0,8 \\
\hline \multirow{5}{*}{$\begin{array}{l}\text { Mevcut Yönetici ile } \\
\text { Geçirilen Süre }\end{array}$} & 1 yıldan az & 34 & 27,6 \\
\hline & 1-3 y1l arası & 44 & 35,8 \\
\hline & $4-6$ y1l arası & 23 & 18,7 \\
\hline & $7-9$ y1l aras 1 & 14 & 11,4 \\
\hline & 10 yıl ve üzeri & 8 & 6,5 \\
\hline \multirow{2}{*}{ Yöneticinin Cinsiyeti } & Kadın & 21 & 17,1 \\
\hline & Erkek & 102 & 82,9 \\
\hline \multirow{5}{*}{ Toplam İş Deneyimi } & 1 yildan az & 19 & 15,4 \\
\hline & 1-3 y1l aras1 & 35 & 28,5 \\
\hline & $4-6$ y1l aras1 & 27 & 22,0 \\
\hline & $7-9$ yıl arası & 19 & 15,4 \\
\hline & 10 yıl ve üzeri & 23 & 18,7 \\
\hline \multirow{2}{*}{ Şirketteki Pozisyonu } & Beyaz yakalı & 36 & 29,3 \\
\hline & Mavi yakalı & 87 & 70,7 \\
\hline
\end{tabular}

B. Veri Toplama Araçları

Katılımcıların paternalist liderlik algılarını ölçmek üzere örnekleme Aycan ve arkadaşları (2013) tarafından geliştirilen Paternalist Liderlik Ölçeği kısaltılmış formu uygulanmıştır. Ölçek; "iş yerinde aile ortamı", "iş dişı yaşama katılma", "sadakat ve itaat beklentisi" olmak üzere üç alt boyuttan ve 10 maddeden oluşmaktadır. Katılımcılardan, ölçekte bulunan ifadelerin kendi durumları ile ne ölçüde örtüştüğünü, "hiç katılmıyorum" düzeyinden "tamamen katılıyorum" düzeyine uzanan beşli Likert tipi bir ölçek üzerinde belirtmeleri istenmiştir. 
Aycan ve arkadaşları (2013) tarafından yapılan çalışmada ölçeğin Cronbach's alpha değeri 0,83 'tür. Bu araştırmada elde edilen veriler ile yapılan güvenilirlik analizlerinde ölçeğin tamamı için elde edilen Cronbach's alpha değeri 0,92 'dir. Alt boyutlara ait değerler ise şöyledir: İş yerinde aile ortamı $(0,92)$, iş dışı yaşama katılma $(0,87)$, sadakat ve itaat beklentisi $(0,61)$. Ölçeğin üç faktörlü yapısını doğrulamak için doğrulayıcı faktör analizi yapılmıştır. Analiz sırasında ölçek maddelerinden biri, düşük faktör yüklemesi $(0,380)$ sebebiyle ölçekten çıkarılmış; analizlere 9 maddeli ve üç boyutlu yapı üzerinden devam edilmiştir. Amos programının sunduğu modifikasyon önerileri doğrultusunda birinci ve ikinci maddelerin hata varyansları birleştirilmiştir. Yapılan nihai analiz sonucu elde edilen uyum iyiliği değerlerinin kabul edilebilir sınırlar içerisinde olduğu görülmüştür (RMSEA=,073; $\chi^{2}=37,935 ; \chi^{2} / \mathrm{df}=1,649 ; \mathrm{CFI}=, 98 \mathrm{GFI}=, 94$ ). Şekil 1, ikinci düzey doğrulayıcı faktör analizi (DFA) sonucunu özetlemektedir.

Şekil 1: Paternalist Liderlik Ölçeği 2. Düzey DFA Sonucu

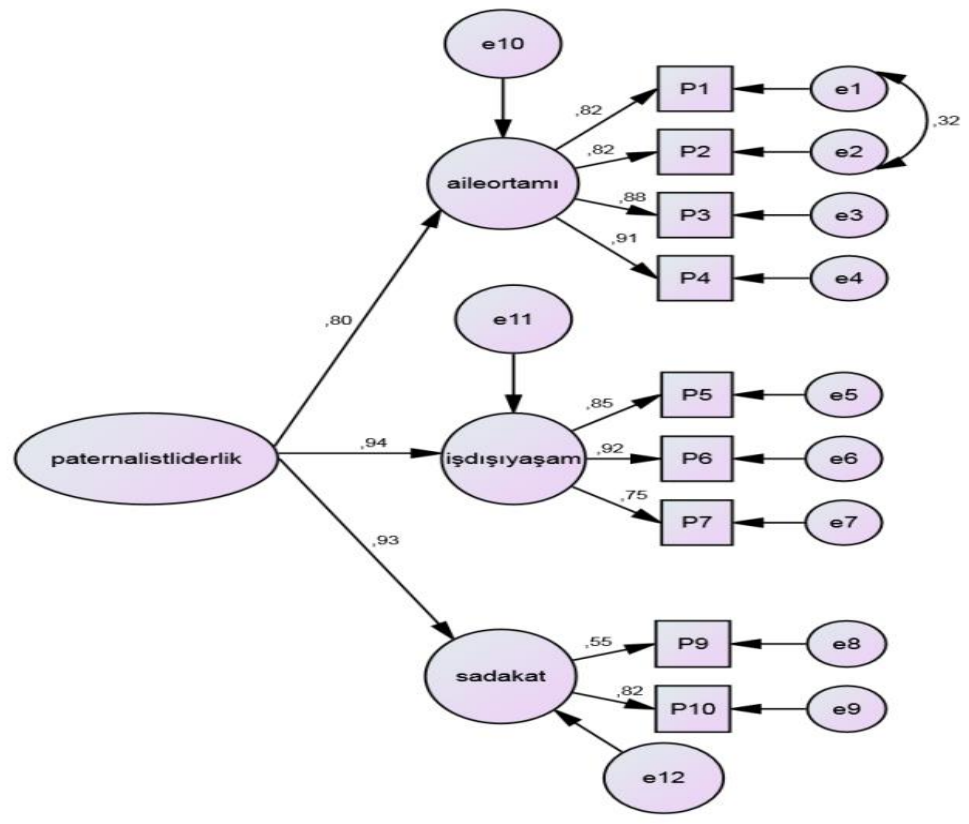

Araştırmada kullanılan diğer ölçek, Van Dyne ve LePine (1998) tarafından oluşturulmuş olan çalışan sesliliği ölçeğidir. Bu çalışmada ölçeğin Arslan ve Yener (2016) tarafından Türkçeye uyarlanmış hali kullanılmıştır. 6 maddeden oluşan ölçek tek boyutlu olarak tasarlanmıştır. Katılımcılardan, söz konusu 6 ifadeye ne ölçüde katıldıklarını beşli Likert tipi bir ölçek üzerinde belirtmeleri istenmiş̧ir. Arslan ve Yener'in (2016) araştırmasında ölçeğin Cronbach's alpha değeri 0,73 olarak hesaplanmıştır. $\mathrm{Bu}$ araştırmada elde edilen verilerle yapılan güvenilirlik analizi sonucu ölçeğin Cronbach's alpha değeri 0,89 olarak bulunmuştur. Ölçeğin tek boyutlu yapısını doğrulamak üzere birinci düzey doğrulayıcı faktör analizi yapılmıştır. Programın modifikasyon önerileri doğrultusunda üç maddenin hata varyansları birleştirilmiştir. Son durumda modelin uyum iyiliği değerlerinin kabul 
edilebilir sınırlar içerisinde olduğu görülmüştür (RMSEA=,047; $\quad \chi^{2}=, 8,902$; $\left.\chi^{2} / \mathrm{df}=1,272 ; \mathrm{CFI}=, 99 \mathrm{GFI}=, 98\right)$. Şekil 2, çalışan sesliliği ölçeği ile gerçekleştirilen birinci düzey doğrulayıcı faktör analizinin sonuçlarını özetlemektedir.

Şekil 2: Çalışan Sesliliği Ölçeği 1. Düzey DFA Sonucu

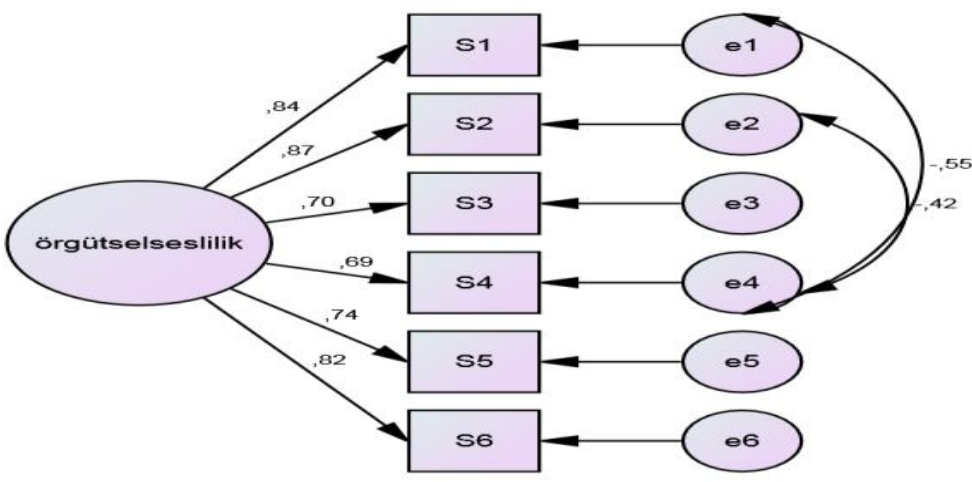

\section{Bulgular}

Araştırma değişkenlerine ait çarpıklık ve basıklık değerlerinin (cinsiyet: çarp1klık=-,351, basıklık=-,1,908; yaş: çarp1kl1k=,402, basılklık=-,540; medeni durum: çarp1kl1k=,716, basıkl1k=-1,512; eğitim durumu: çarp $1 \mathrm{kl1k}=, 897$, basılkl1k=,329; mevcut yönetici ile geçirilen süre: çarp $1 \mathrm{kl} 1 \mathrm{k}=, 706$, bas1kl1k=-,346;yöneticinin cinsiyeti: çarp $1 \mathrm{kl} 1 \mathrm{k}=-1,772$, bası $1 \mathrm{kl} 1 \mathrm{k}=1,158$; toplam iş deneyimi: çarp $1 \mathrm{k} 11 \mathrm{k}=, 202$, basılkl1k=-1,153; şirketteki pozisyon: çarp $1 \mathrm{kl1}=-, 923$, bas1kl1k=-1,168; iş yerinde aile ortamı: çarp1kl1k=-1,198; basıkl1k=1,538; iş dışı yaşama dahil olma: çarp $1 \mathrm{kl} 1 \mathrm{k}=-, 963$, bas $1 \mathrm{kl1k}=1,459$; sadakat ve itaat beklentisi: çarp1kl1k=-,275, basılkl1k=-,224; paternalist liderlik: çarp1kl1k=-,543, basılkl1k=-,006, çallşan sesliliği: çarp $1 \mathrm{kl} 1 \mathrm{k}=-, 709$, basıklık=1,226) +2 ve -2 değerleri arasında değiştiği; dolayısıyla normal dağılıma uygunluk koşulunu yerine getirdikleri görülmüştür (George ve Mallery, 2010).

Araştırmada kullanılan ölçekler ve bunlara ait alt boyutlarla elde edilen değişkenlerin ortalamalarında demografik faktörlere göre anlamlı farklılıklar bulunup bulunmadığını anlamak için t-testleri ve ANOVA analizleri yapılmıştır. Cinsiyet değişkeni baz alınarak yapılan t-testine göre kadın ve erkek katılımcıların seslilik ortalamaları arasında anlamlı bir fark bulunmamaktadır. Diğer taraftan, erkek katılımcıların paternalist liderlik algılarına ilişkin puanlarının kadınlara oranla yüksek olduğu görülmüştür $\left(\mathrm{t}_{(121)}=-2,523 ; \mathrm{p}<0,05\right.$; kadın ort. $=3,93$, erkek ort.=4,23). Paternalist liderlik ölçeğinin alt boyutlarından hangileri arasında fark olduğuna bakılmış; iş dış1 yaşama katılma $\left(\mathrm{t}_{(121)}=-2,715 ; \mathrm{p}<0,05\right.$; kadın ort. $=3,82$, erkek ort. $=4,20)$ ile sadakat ve itaat beklentisi $\left(\mathrm{t}_{(121)}=-2,198 ; \mathrm{p}<0,05 ;\right.$ kadın ort. $=3,91$, erkek ort. $=4,18$ ) alt boyutlarında erkeklerin puanlarının kadınlara oranla anlamlı düzeyde yüksek olduğu görülmüştür. Katılımcıların medeni durumu baz alınarak yapılan t-testi sonucunda iş dışı yaşama katılma ve çalışan sesliliği değişkenlerinde anlamlı farklılıklar olduğu görülmüştür. Buna göre, evlilerin iş dış1 
yaşama katılma skorları $\left(\mathrm{t}_{(121)}=-2,071 ; \mathrm{p}<0,05\right.$; evli ort. $=4,15$, bekar ort. $\left.=3,81\right) \mathrm{da}$ seslilik skorları da $\left(\mathrm{t}_{(121)}=-2,164 ; \mathrm{p}<0,05\right.$; evli ort. $=4,25$, bekar ort. $\left.=3,94\right)$ bekarlara göre anlamlı düzeyde yüksektir. Yapılan t-testlerinde, katılımcıların skorlarının yaş, yöneticinin cinsiyeti ve şirketteki pozisyon değişkenlerine göre anlamlı bir farklılık göstermediği tespit edilmiştir. Yapılan ANOVA analizleri sonucunda, katılımcıların eğitim durumu, mevcut yönetici ile çalışma süresi ve toplam iş deneyimine ilişkin farklılıklarının çalışan sesliliği veya paternalist liderlik algısı değişkenlerinde anlamlı bir farklılığa yol açmadığı görülmüştür.

Araştırma değişkenleri arasındaki ilişkileri ve bunların yönünü tespit etmek için korelasyon analizi yapılmıştır. Değişkenlere ait ortalama, standart sapma ve korelasyon katsayıları Tablo 2'de gösterilmiştir.

Tablo 2: Araştırma Değişkenleri Arasındaki Korelasyonlar

\begin{tabular}{|c|c|c|c|c|c|c|c|c|c|c|c|c|c|}
\hline Değişkenler & 1 & 2 & 3 & 4 & 5 & 6 & 7 & 8 & 9 & 10 & 11 & 12 & 13 \\
\hline 1. Cinsiyet & $\cdot$ & & & & & & & & & & & & \\
\hline 2. Yaş &, $166^{\star}$ & - & & & & & & & & & & & \\
\hline 3.Medeni D. & 035 &,$- 637^{*+}$ & - & & & & & & & & & & \\
\hline 4. Eğitiom D. & -054 & $-346^{+*}$ &, $305^{* *}$ & - & & & & & & & & & \\
\hline 5.Yön. ile Çal. S. &, 112 &, $360^{* *}$ &,$- 302^{* *}$ & -058 & - & & & & & & & & \\
\hline 6.Yöneticinin Cin. &, 101 &, $271^{* *}$ &,$- 275^{+*}$ & -021 &, $201^{*}$ & - & & & & & & & \\
\hline 7.Toplam İş Den. &, 008 &, $341^{* *}$ &,$- 326^{*+}$ &, 133 &, $599^{+*}$ &, $236^{* *}$ & - & & & & & & \\
\hline 8.Şirketteki Poz. & $=034$ & 006 &, 152 &,$- 412^{* *}$ & $=030$ & 041 &,$- 191^{*}$ & - & & & & & \\
\hline 9.İs Yer. Aile Ort. &, $161^{*}$ &, 002 & -091 & 003 &, 070 &, $233^{* *}$ & ;,022 &,- 006 & . & & & & \\
\hline 10.I̦ D̦ Diș1 Yaș. Kat. &, $240^{* *}$ &, $225^{\star}$ &,$- 205^{\star}$ & -123 &, $181^{*}$ & 069 & 072 & 011 & $647^{*+}$ & - & & & \\
\hline 11.Sad. İtaat Bek. &, $196^{\star}$ & 089 & -136 &,$- 220^{\star}$ & 017 & 094 & -058 &, 053 &, $536^{4+}$ & $686^{* *}$ & - & & \\
\hline 12.Paternalist Lid. &, $224^{*}$ &, 111 &,- 160 &,- 097 &, 112 &, 171 & ,004 &, 013 &, $900^{* *}$ &, $890^{*+}$ &, $779^{* *}$ & - & \\
\hline 13.Çalıșan Sesliliği &, 170 &, $195^{\star}$ &,$- 217^{i *}$ &,- 026 &, 073 &, 163 &, 128 & -119 &, $501^{* *}$ &, $612^{* *}$ &, $490^{* *}$ &, $615^{\text {*i }}$ & - \\
\hline Ortalama & 1,59 & 35,4 & 1,33 & 1,95 & 2,33 & 1,83 & 2,94 & 1,71 & 4,17 & 4,04 & 4,07 & 4,11 & 4,15 \\
\hline Standart Sapma & 0,67 & 0,49 & 10,3 & 0,47 & 1,26 & 1,19 & 0,38 & 1,35 & 0,46 & 0,78 & 0,79 & 0,66 & 0,68 \\
\hline
\end{tabular}

$*_{p}<, 05 ; * * p<, 01 ; \quad N=12$

Tabloda görüldüğ̈̈ üzere, araştırma verileri ile hesaplanan toplam paternalist liderlik algısı değişkeni ile çalışan sesliliği değişkeni arasında pozitif yönlü anlamlı bir ilişki vardır $(\mathrm{r}(123)=, 615, \mathrm{p}<, 01)$. Paternalist liderlik algısının alt boyutları olan iş yerinde aile ortamı $(\mathrm{r}(123)=, 501, \mathrm{p}<, 01)$, iş dışı yaşama katılma $(\mathrm{r}(123)=, 612, \mathrm{p}<, 01)$, sadakat ve itaat beklentisi $(\mathrm{r}(123)=, 490, \mathrm{p}<, 01)$ değişkenleri ile çalışan sesliliği arasında da benzer şekilde pozitif yönlü anlamlı ilişkiler tespit edilmiştir. Böylece araştırma verilerinin $H_{1}, H_{2}$ ve $H_{3}$ hipotezlerini desteklediği görülmüştür.

Paternalist liderlik algısının alt boyutları olan iş yerinde aile ortamı, iş dışı yaşama katılma, sadakat ve itaat beklentisi değişkenlerinin, çalışan sesliliği 
üzerindeki etkisini tespit etmek için hiyerarşik regresyon analizi yapılmıştır. Analizin sonuçları Tablo 3'te gösterilmiştir.

Tablo 3: Hiyerarşik Regresyon Analizi Sonuçları

\begin{tabular}{|c|c|c|c|c|c|c|}
\hline \multirow{3}{*}{ Değişkenler } & \multicolumn{6}{|c|}{ Çalıșan Sesliliği } \\
\hline & \multicolumn{3}{|c|}{ Model 1} & \multicolumn{3}{|c|}{ Model 2} \\
\hline & B & S. H. & $\boldsymbol{\beta}$ & B & S. H. & $\beta$ \\
\hline Cinsiyet & ,221 &, 127 &, 162 & ,026 & ,104 & ,019 \\
\hline Yaş &, 003 & ,008 & 049 &, 004 &, 007 & ,061 \\
\hline Medeni D. &,- 220 &, 181 &,- 155 &,- 059 & 146 &,- 042 \\
\hline Eğitim D. &, 001 &, 071 &, 002 &, 015 & 058 & 023 \\
\hline Yön. ile Çal. S. &,- 039 &, 065 &,- 069 &,- 079 & 053 &,- 140 \\
\hline Yöneticinin Cin. &, 166 &, 171 & ,093 &, 106 & 144 & 059 \\
\hline Toplam İş Den. & ,031 &, 060 &, 063 &, 061 & 048 &, 122 \\
\hline Şirketteki Poz. &,- 122 &, 155 &,- 083 &,- 140 & 124 &,- 095 \\
\hline İş Yer. Aile Ort. & & & &, 137 & 088 &, 159 \\
\hline İş Dıșı Yaş. Kat. & & & & 357 & 101 & ,419* \\
\hline Sad.ve İtaat Bek. & & & &, 115 & 102 &, 116 \\
\hline $\mathbf{R}$ & \multicolumn{3}{|c|}{,314 } & \multicolumn{3}{|c|}{,665 } \\
\hline $\mathbf{R}^{2}$ & \multicolumn{3}{|c|}{,099 } & \multicolumn{3}{|c|}{,443 } \\
\hline$\Delta \mathbf{R}^{2}$ & \multicolumn{3}{|c|}{,099 } & \multicolumn{3}{|c|}{,344 } \\
\hline Düzeltilmiş $\mathbf{R}^{2}$ & \multicolumn{3}{|c|}{, 035} & \multicolumn{3}{|c|}{,387 } \\
\hline
\end{tabular}

Hiyerarşik regresyon analizinde birinci adımda, araştırmanın demografik değişkenleri olan cinsiyet, yaş, medeni durum, eğitim durumu, mevcut yönetici ile birlikte sürdürülen çalışma süresi, yöneticinin cinsiyeti, toplam iş deneyimi ve çalışanın şirketteki pozisyonu modele dahil edilmiştir. Analiz sonucu, söz konusu değişkenlerin regresyon modeline anlamlı katkı yapmadıklarını göstermiştir $\left[\mathrm{F}_{(8,114)}=1,56, \mathrm{p}=, 145>0,05\right]$. İkinci adımda ise demografik değişkenlerin yanı sıra modele paternalist liderlik algısının üç alt boyutunu oluşturan, iş yerinde aile ortamı yaratma, iş dışı yaşama katılma, sadakat ve itaat beklentisi değişkenleri de dahil edilmiştir. Böylece, demografik değişkenlerin çalışan sesliliği üzerindeki etkisi kontrol edilirken, paternalist liderlik algısının çalışan sesliliği üzerindeki etkisi tespit edilmiştir. İkinci modelin istatistiksel olarak anlamlı olduğu görülmüştür $\left[\mathrm{F}_{(11,114)}=8,01, \mathrm{p}=, 000<0,05\right]$. İkinci grupta yer alan değişkenlerin regresyona girmesi ile birlikte modelin açıklama gücünde önemli bir artış gözlenmiştir. Buna göre, paternalist liderlik algısının alt boyutlarının modele girmesi, çalışan sesliliğindeki \%34'lük ilave varyansı açıklamıştır. Bütün bağımsız değişkenlerin regresyona dahil olduğu bu modelde yalnızca iş dişı yaşama katılma $(\beta=0,419$, $\mathrm{p}<0,05)$ değişkeninin modele anlamlı katkı sağladığı anlaşılmaktadır. Tüm bağımsız değişkenlerin, çalışan sesliliğinde yaklaşık \%39'luk varyansı açıladığı bulunmuştur. Böylece araştırma verilerinin $H_{4}$ hipotezini kısmen desteklediği söylenebilir.

\section{SONUÇ ve ÖNERILER}

$\mathrm{Bu}$ çalışma temel olarak paternalist liderliğin alt boyutları olan iş yerinde aile ortamı, iş dışı yaşama katılma ve sadakat ve itaat beklentisi değişkenleri ile çalışan sesliliği arasındaki ilişkiye odaklanmaktadır. Sonuçlar, çalışan sesliliğinin her üç boyut ile pozitif yönlü korelasyon gösterdiğini ortaya koymaktadır. Diğer yandan, gerçekleştirilen regresyon analizi, çalışan sesliliğine anlamlı katkı sağlayan tek alt boyutun iş dışı yaşama katılma boyutu olduğunu göstermiştir. $\mathrm{Bu}$ 
durumda, liderin astlarına özel hayatlarını da kapsayan bütüncül bir ilgi göstermesinin, çalışanların yapıcı fikirlerini paylaşma ve böylece örgüte katkı sağlama sorumluluğunu ve bağlılığını gösterme eğilimlerinde anlamlı bir artışa neden olduğu söylenebilir. Bu hali ile araştırmanın sonuçları, Liu ve Liu (2017) araştırmasının paternalist liderliğin yardımseverlik boyutunun çalışan sesliliği üzerinde pozitif yönlü anlamlı etkisi olduğu yönündeki bulguları ile örtüşmektedir. Söz konusu araştırmada yer alan yardımseverlik boyutu, liderin astlarına iş ilişkisinin ötesinde aile yaşamını da kapsayacak şekilde kişisel bir ilgi göstermesi ve bir problem yaşamaları durumunda kaygı ve destek göstermesi olarak açıklanabilir.

Araştırmanın özgün değerinin, yazında gölgede kalmış bir alan olan seslilik ve paternalist liderlik konularında çalışanların tutum ve algılarına ilişkin bulgular sunması ve iki kavram arasındaki ilişkiye 1şı tutuyor olmasında yattığ düşünülmektedir. Araştırmanın tek bir sektörde gerçekleştirilmiş olması, gıda sektörüne ilişkin saf veriler sağlaması bakımından olumlu olmakla birlikte, örneklemin dar tutulmasına neden olması bakımından bir kısit sayılabilir. Dolayısıyla daha geniş örneklemlerle ve farklı sektörlerde gerçekleştirilecek araştırmalar literatüre katkı sağlayacaktır. Ayrıca, söz konusu değişkenler arasındaki ilişkide rol oynaması muhtemel diğer değişkenleri de hesaba katarak kurgulanacak modellerin literatürü zenginleştireceği söylenebilir. Örneğin, kültür ile çok yakından ilişkili bir olgu olan paternalist liderlik ile seslilik arasındaki ilişkide, çalışanların belirsizlikten kaçınma, güç mesafesi, kolektivizm skorları gibi bireysel değişkenlerin nasıl bir rol oynadığı ileriki araştırmalarla aydınlatılabilir.

\section{KAYNAKÇA}

Apaydın, E. (2017). Paternalistik Liderliğin Değişime Direnç Üzerine Etkileri: Örgütsel Güvenin Aracılık Rolü. (Yayımlanmamış Yüksek Lisans Tezi). Bahçeşehir Üniversitesi Sosyal Bilimler Enstitüsü, İstanbul.

Arslan, A.\& Yener, S. (2016). İşgören Sesliliği Ölçeğinin Türkçeye Uyarlanması Çalışması. Yönetim ve Ekonomi Araştırmaları Dergisi, 14(1): 173-191.

Aycan, Z. (2006). Paternalism: Towards Conceptual Refinement and Operationalization. (Ed. K. S. Yang, K. K. Hwang, \& U. Kim), Indigenous and Cultural Psychology: Understanding People in Context, ss. 445-466, Springer, New York.

Aycan, Z. \& Kanungo, R., N. (2000). Toplumsal Kültürün Kurumsal Kültür ve İnsan Kaynakları Uygulamaları Üzerine Etkileri, (Ed. Z. Aycan), Akademisyenler ve Profesyoneller Bakış Açıslyla Türkiye'de Yönetim, Liderlik ve İnsan Kaynakları Uygulamaları, ss.25-53, Türk Psikologlar Derneği Yayınları, Ankara.

Aycan, Z., Schyns, B., Sun, J., Felfe, J.\& Saher, N. (2013). Convergence and Divergence of Paternalistic Leadership: A Cross-Cultural Investigation of Prototypes. Journal of International Business Studies, 44: 962-969.

Bulut, H. \& Meydan, C. H. (2018). Liderlik Tarzlarının Çalışanların Ses Verme Davranışlarına Etkisi: Kamuda Bir Araştırma. Ankara Üniversitesi SBF Dergisi, 3(1): 223-244.

Chan, S. C. (2013). Paternalistic Leadership and Employee Voice: Does Information Sharing Matter? Human Relations, 67(6): 667-693.

Detert, J. R.\& Burris, E. R. (2007), Leadership Behavior and Employee Voice: Is the Door Really Open? Academy of Management Journal, 50(4): 869-884.

Duan, J., Kwan, H. K. \& Ling, B. (2014). The Role of Voice Efficacy in the Formation of Voice Behaviour: A Cross-Level Examination. Journal of Management \& Organization, 20(4): 526-543. 
Duanxu, W., Gan, C., Wu, C. \& Wang, D. (2015). Ethical Leadership and Employee Voice: Employee Self-Efficacyand Self-Impact as Mediators. Psychological Reports, 116(3): 751-767.

Dutton, J. E., Ashford, S. J., O’Neill, R. M., Hayes, E. \& Wierba, E. E. (1997). Reading the Wind: How Middle Managers Assess the Contextfor Selling Issues to Top Managers. Strategic Management Journal,18(5): 407-425.

Ergül, A., Kartal, C. \& Gökdeniz, İ. (2017). Çalışanların Ses Çıkarma Davranışının Zaman Hırsızlığına Olan Etkisi. İş'te Davranış Dergisi, 2(1): 80-89.

Farh, J. L. \& Cheng, B. S. (2000). A Cultural Analysis of Paternalistic Leadership in Chinese Organizations, (Ed. J. T. Li; A. S. Tsui \& E. Weldon), Management and Organizations in the Chinese Context, ss. 84-127, Macmillan, London.

Farndale, E., Van Ruiten, J., Kelliher, C. \& Hope-Hailey, V. (2011). The Influence of Perceived Employee Voice on Organizational Commitment: An Exchange Perspective. Human Resource Management, 50(1): 113-129.

Frazier, L. M. \& Fainshmidt, S. (2012). Voice Climate, Work Outcomes and the Mediating Role of Psychological Empowerment: A Multilevel Examination. Group\&Organization Management, 37(6): 691-715.

Fuller, J. B., Marler, L. E. \& Hester, K. (2006). Promoting Felt Responsibility for Constructive Changeand Proactive Behavior: Exploring Aspects of an Elaborated Model of Work Design. Journal of Organizational Behavior, 27: 1089-1120.

Gelfand, M. J., Erez, M. \& Aycan, Z. (2007). Cross-Cultural Organizational Behavior. Annual Review of Psychology, 58: 479-514.

George, D. \& Mallery, M. (2010). SPSS for Windows Step by Step: A Simple Guide and Reference (10thed.), Pearson, Boston, MA.

Gürcan, N. (2018). Türk Kültüründe Paternalist Liderlik Davranışlarının İzleyenlerin Duygusal Bağlllıkları Üzerindeki Etkisi: Y Kuşağına Yönelik Bir Araştırma, (Yayımlanmamış Yüksek Lisans Tezi), Dokuz Eylül Üniversitesi Sosyal Bilimler Enstitüsü, İzmir.

Henderson, L. M. (2013). Enhancing Safety Commuication with Leadership: A QuantitativeStudy of Leadership Style and Safety Voice, (Yayımlanmamış, Doktora Tezi), Phoenix Üniversitesi, Arizona.

Kassing, J. W. (1998). Development and Validation of the Organizational Dissent Scale. Management Communication Quarterly,12(2): 183-229.

LePine, J. A. \& Van Dyne, L. (1998). Predicting Voice Behavior in Work Groups. Journal of Applied Psychology, 83(6): 853-868.

Liu, H. \& Liu, X. (2017) Relationship Between Paternalistic Leadership and Employee's Voice Behavior Based on Regression Analysis. Journal of Discrete Mathematical Sciences and Cryptography, 20(1): 205-215.

Martinez, P. G. (2003). Paternalism as a Positive Form of Leader-Subordinate Exchange: Evidence from Mexico. Journal of the Iberoamerican Academy of Management, 1(3): 227-242.

Morrison, E. W. (2011). Employee Voice Behavior: Integration and Directions for Future Research. The Academy of Management Annals, 5(1): 373-412.

Morrison, E. W. \& Milliken, F. J. (2000). Organizational Slience: A Barrier to Change and Development in a Pluralistic World. The Academy of Management Review, 25(4): 706-725.

Oral Ataç, L. (2018). Çalışan Sesliliği, (Ed. E. Güven \& S. Çavuşoğlu), Yeni Nesil Iş̧letmelerde Güncel Eğilimler, ss.242-234, Beta, İstanbul.

Paşa, S. F., Kabasakal, H. \& Bodur, M. (2001). Society, Organizations, and Leadership in Turkey. Applied Psychology: An International Review, 50(4): 559-589.

Pellegrini, E. K. \& Scandura, T. A. (2006). Leader-Member Exchange, Paternalism and Delegation in the Turkish Business Culture: An Empirical Investigation. Journal of International Business Studies, 37: 264-279.

Pellegrini, E. K., Scandura, T. A. \& Jayaraman, V. (2010). Cross-Cultural Generalizability of Paternalistic Leadership: An Expansion of Leader-Member Exchange Theory. Group \& Organization Management, 35(4):391-420.

Şehitoğlu, Y. (2012). İşgören Sesliliğii, Nedenleri ve Boyutları: Teorik Bir Çerçeve. Karadeniz Teknik Üniversitesi Sosyal Bilimler Dergisi, 4: 27-38. 
Tangirala, S. \& Ramanujam, R. (2008). Exploring Nonlinearity in Employee Voice: The Effects of Personal Control and Organizational Identification. Academy of Management Journal, 51(6): 1189-1203.

Uhl-Bien, M., Tierney, P. S., Graen, G. B. \& Wakabayashi, M. (1990). Company Paternalism and The Hidden-Investment Process: Identification of the "Right Type" for Line Managers in Leading Japenese Organizations. Group Organization Management, 15(4): 414-430.

Van Dyne, L., Ang, S. \& Botero, I. C. (2003). Conceptualizing Employee Silence and Employee Voice as Multidimensional Constructs. Journal of Management Studies, 40(6): 1359-1392.

Van Dyne, L. \& LePine, J. A. (1998). Helping and Voice Extra-Role Behaviors: Evidence of Construct and Predictive Validity. The Academy of Management Journal, 41(1): 108-119.

Xiao, Y.-j., Pan, A.-c. (2017). The Effect of Paternalistic Leadership on Employee Voice Behavior: The Study of the Mediating Role of OBSE. 3rd International Conference on Humanity and Social Science (ICHSS 2017) Bildiriler Kitabl, ss. 89-93.

Westwood, R. (1997). Harmony and Patriarchy: The Cultural Basisfor Paternalist Headship Among the Overseas Chinese. Organization Studies, 18(3): 445-480.

Zhang, Y., Huai, M.-y., \& Xie, Y.-h. (2015). Paternalistic Leadership and Employee Voice in China: A Dual Process Model. The Leadership Quarterly, 26(1): 25-36.

\section{SUMMARY}

Under the current conditions, it is very difficult for the leader to dominate the work done in an organization. The leader's need for subordinates' thoughts and views on the quality of the decisions and the effectiveness of the organization has increased. In addition, for today's high-profile employees, the practice of having a say in work-related issues has become an important factor shaping work motivation and attitude towards the organization. At this point, the concept of employee voice, which can be defined as employees' expression of their knowledge, opinions and suggestions with a positive attitude and proactive approach, emerges as an important phenomenon.

It is known that paternalists values of our culture can be felt in business life as well, as they are and important factor shaping the organizational culture in our country. Research shows that the employees of our country, including those representing the young generation, expect paternalistic attitudes from their leaders such as making them feel family warmth or sharing their needs for both professional and private life. In this sense, the paternalist leadership model, which integrates discipline and authority with paternal interest and charity, has a special importance in understanding the prevailing leadership climate in our country. Nevertheless, the way in which voice behavior occurs within the leadership communication is largely obscured.

This study aims to reveal the possible effect of paternalistic leadership perception on employee vocalism. In this context, the study seeks to answer questions such as whether there is a relationship between employee perceptions of paternalist leadership and related sub dimensions and employee voice; if any, what is the direction of these relationships; are these variables considered statistically significant in explaining employee voice. For this purpose, data were collected from 123 people working in food sector in Manisa. The questionnaire applied to the research sample consists of two scales and 8 demographic questions. Paternalist leadership scale and employee voice scale were used in the study. Correlation 
analysis was used to examine the relationship between subdimensions of paternalistic leadership and employee voice, and hierarchical regression analysis was used to examine the effect of paternalistic leadership perception on employee voice behavior. The t-tests and ANOVA analyzes were performed in order to determine whether there were significant differences in the means of the variables obtained with the scales used in the study and their sub-dimensions according to demographic factors. The results show that employee voice correlates positively with all three sub-dimensions of paternalistic leadership. In the regression analysis, it was seen that the only dimension that contributed significantly to employee voice was the dimension of participation in non-work life. 